\title{
Grain refinement and strengthening of austenitic stainless steels during large strain cold rolling
}

\author{
Marina Odnobokova, Andrey Belyakov (D) and Rustam Kaibyshev
}

Laboratory of Mechanical Properties of Nanostructured Materials and Superalloys, Belgorod State

University, Belgorod, Russia

\begin{abstract}
The microstructure/texture evolution and strengthening of 316 L-type and 304 L-type austenitic stainless steels during cold rolling were studied. The cold rolling was accompanied by the deformation twinning and micro-shear banding followed by the strain-induced martensitic transformation, leading to nanocrystalline microstructures consisting of flattened austenite and martensite grains. The fraction of ultrafine grains can be expressed by a modified JohnsonMehl-Avrami-Kolmogorov equation, while inverse exponential function holds as a first approximation between the mean grain size (austenite or martensite) and the total strain. The deformation austenite was characterised by the texture components of Brass, $\{011\}<211\rangle$, Goss, $\{011\}<100\rangle$, and $S,\{123\}<634>$, whereas the deformation martensite exhibited a strong $\{223\}<110>$ texture component along with remarkable $\gamma$-fibre, $<111>\| N D$, with a maximum at $\{111\}<211>$. The grain refinement during cold rolling led to substantial strengthening, which could be expressed by a summation of the austenite and martensite strengthening contributions.
\end{abstract}

\section{ARTICLE HISTORY}

Received 17 August 2018

Accepted 6 November 2018

\section{KEYWORDS}

Austenitic stainless steel; deformation twinning; shear bands; strain-induced martensite; ultrafine grains; texture; strength

\section{Introduction}

Austenitic chromium-nickel steels are one of the most important and frequently used stainless steels because of their good combinations of ductility, toughness, formability, weldability and corrosion resistance [1]. The most widespread representatives of the austenitic stainless steels are types of $316 \mathrm{~L} / 304 \mathrm{~L}$ steels. The conventional heat treatment of austenitic steels consisting of solution treatment at $1273-1373 \mathrm{~K}$ followed by rapid cooling results in a carbide-free microstructure with a homogeneous distribution of the alloying elements that provides excellent corrosion resistance. On the other hand, austenitic stainless steels with well annealed/recrystallized microstructures exhibit relatively low yield strength [2]. The yield strength

CONTACT Marina Odnobokova odnobokova@bsu.edu.ru Belgorod State University, Pobeda 85, Belgorod 308015, Russia 
strain hardening, deformation twinning and strain-induced martensite. The deformation microstructures and the dislocation densities in the cold worked steels depend on stacking fault energy (SFE) [1,3,4]. Austenitic stainless steels are characterised by relatively low SFE ranging from approx. $20 \mathrm{~mJ} / \mathrm{m}^{2}$ to $50 \mathrm{~mJ} / \mathrm{m}^{2}$ [5]. Low SFE promotes the partial slip and, therefore, suppresses dynamic recovery. Following rapid increase in the dislocation density, the deformation twinning and the strain-induced martensitic transformation may occur in austenitic stainless steels during cold deformation. The strain-induced martensite readily develops in deformation micro-shear bands, which result from in-grain localisation of the plastic flow, or deformation twins and, especially, at twins/microbands intersections $[6,7]$. The frequent deformation twinning and strain-induced martensitic transformation during cold working of austenitic stainless steels result in subdivision of original microstructures into ultrafine crystallites with a size of below $0.1 \mu \mathrm{m}$ [8-12]. Such microstructure refinement along with high dislocation density in the cold worked steels provides substantial strengthening. The strength of cold worked stainless steels may exceed 2 GPa $[8,10,13-16]$.

The deformation textures that develop in austenitic stainless steels during cold rolling also depend on SFE. Namely, the high value of SFE leads to a Copper-type texture $(\{112\}<111>)$, whereas low SFE results in a Brass-type texture $(\{011\}<211>)[17,18]$. The developed textures are closely related to the deformation microstructures/substructures $[19,20]$. The shear-banding, which starts from micro-shearing within a grain and progressively propagates over neighbouring grains that may lead to macro-shear bands with an increase in rolling reduction, is accompanied by an increase in the fraction of $\gamma$-fibre texture component $(<111>\| \mathrm{ND})$ involving the $\mathrm{E}(\{111\}<110>)$ and $\mathrm{F}$ $(\{111\}<211>)$ orientations in low SFE austenitic steels [21-24]. It should be noted that the effect of cold rolling on the textural changes was clarified on rather stable austenite, whereas meta-stable austenitic stainless steels have not been studied in sufficient detail. The development of strain-induced martensite during cold working may significantly alternate the deformation textures. The strain-induced martensite may itself contribute remarkably to overall properties of the cold worked semi-products, which are made of meta-stable austenitic stainless steels. However, the microstructure and texture evolution in strain-induced martensite during large strain cold rolling have not been elaborated comprehensively. Thus, the aim of the present work is to study the relationship between structural changes, texture evolution and strengthening of chromium-nickel meta-stable austenitic stainless steels processed by large strain cold rolling. Two typical steel representatives with different austenite stability are used to reveal undoubtedly the effect of strain-induced martensite on the regularities of microstructure/texture development and work hardening. 


\section{Experimental}

A $316 \mathrm{~L}$-type austenitic steel, Fe-0.04\%C-17.3\%Cr-10.7\%Ni-1.7\%Mn-0.4\%Si0.04\%P-0.05\%S-2\%Mo (all in wt.\%), and a $304 \mathrm{~L}$-type austenitic steel, Fe$0.05 \% \mathrm{C}-18.2 \% \mathrm{Cr}-8.8 \% \mathrm{Ni}-1.65 \% \mathrm{Mn}-0.43 \% \mathrm{Si}-0.05 \% \mathrm{P}-0.04 \% \mathrm{~S}$ (all in wt.\%), were chosen in the present investigation as typical representatives of widely used austenitic stainless steels with different austenite stability. According to an empirical relation, $\mathrm{SFE}=-53+6.2 \% \mathrm{Ni}+0.7 \% \mathrm{Cr}+3.2 \% \mathrm{Mn}+9.3 \% \mathrm{Mo}$, proposed by Schramm and Reed [5], SFE were calculated as $50 \mathrm{~mJ} / \mathrm{m}^{2}$ and $24 \mathrm{~mJ} / \mathrm{m}^{2}$ for the present $316 \mathrm{~L}$-type and $304 \mathrm{~L}$-type steels, respectively. Note here that Schramm and Reed considered only major alloying elements for steels with carbon from $0.03 \%$ to $0.08 \%$ and nickel below $20 \%$. The steels were hot forged at $1373 \mathrm{~K}$ followed by air cooling to produce a uniform microstructure with the mean grain size of $21 \mu \mathrm{m}$ in $316 \mathrm{~L}$ steel and $24 \mu \mathrm{m}$ in $304 \mathrm{~L}$ steel. The plate rolling was carried out on the samples with an initial thickness $30 \mathrm{~mm}$ at room temperature to various total true strains of $\varepsilon=\ln \left(h_{0} / h_{\varepsilon}\right)$, where $h_{0}$ and $h_{\varepsilon}$ are the initial and final thickness of the rolled samples.

The microstructural characterisation was performed using a JEM-2100 transmission electron microscope (TEM) operating at $200 \mathrm{kV}$ and a Nova Nanosem 450 scanning electron microscope (SEM) equipped with an electron back-scattered diffraction (EBSD) detector on the sample sections normal to the transverse direction (TD), i,e on ND-RD planes, where $\mathrm{ND}$ and $\mathrm{RD}$ are the normal and rolling directions, respectively. The EBSD patterns were acquired from arbitrary selected representative areas of the deformation microstructures with step sizes of $200 \mathrm{~nm}$ after total strains of $0.5,60 \mathrm{~nm}$ after total strains of 1.0, $50 \mathrm{~nm}$ after total strains of 2.0, and $40 \mathrm{~nm}$ after total strains of 3.0. Each EBSP map, which was used in the present study to characterise the microstructure evolved at total strains of $1-3$, covered at least 3000 grains. The TEM foils and the SEM specimens were prepared from $3.0 \times 1.5 \mathrm{~mm}^{2}$ rectangular plate samples by electro-polishing at room temperature using a solution of $10 \%$ perchloric acid in glacial acetic acid with Struers Tenupol-5 double jet unit at a voltage of $20 \mathrm{~V}$. The volume fractions of the strain-induced martensite were averaged through X-ray analysis, magnetic induction method and EBSD technique. The microstructure and micro-texture measurements were carried out using an orientation imaging microscopy (OIM) with TSL OIM Analysis 6 software. The OIM images were subjected to cleanup procedure setting a minimal confidence index of 0.1. In addition to OIM, the orientations and misorientations among the deformation grains/subgrains were analysed by conventional TEM Kikuchi-line method with a technique of converged beam [25]. The mechanical properties of processed samples were evaluated by means of tensile tests using flat specimens with a gauge length of $16 \mathrm{~mm}$ and a cross-section of $3.0 \times$ $1.5 \mathrm{~mm}^{2}$ with the tensile axis parallel to $\mathrm{RD}$. The tensile tests were carried out at 
room temperature using an Instron 5882 testing machine recording the load and the crosshead displacement with a crosshead rate of $2 \mathrm{~mm} / \mathrm{min}$ (initial strain rate of $\left.2 \times 10^{-3} \mathrm{~s}^{-1}\right)$.

\section{Results}

\subsection{Deformation microstructures}

Typical deformation microstructure developed in the $304 \mathrm{~L}$ austenitic stainless steel during cold rolling to a strain of 0.5 is shown in Figure 1. The cold working leads to an elongation of original grains toward the rolling direction that is accompanied by the development of high dislocation densities and deformation twinning. The selected area electron diffraction pattern in Figure 1 clearly shows the evolution of high density deformation twins with $\{111\}$ twin planes aligned at about $45^{\circ}$ to the rolling direction (RD). The active twinning system in each grain has been shown to depend on the grain orientation with respect to the rolling direction [17], whereas an increase in rolling reduction has been accompanied by an alignment of twins along the rolling plane [2124]. The operation of deformation twinning at an early deformation results in rapid subdivision of original grains into fragments separated by thin (about $40-50 \mathrm{~nm}$ ) twins, followed by the evolution of lamellar microstructure as the number of twins increases.

Cold rolling to total strains of 1 flattens the original grains and leads to the development of micro-shear bands (Figures 2(a) and 3(a)). The latter ones have been considered as preferential nucleation sites for the strain-induced

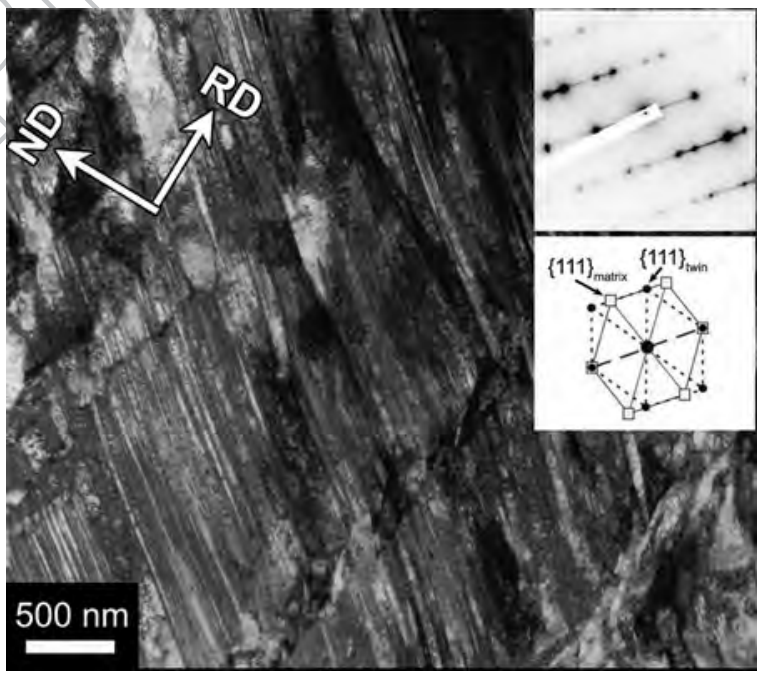

Figure 1. Deformation twinning in a $304 \mathrm{~L}$ stainless steel during cold rolling to a strain of 0.5 . ND and $\mathrm{RD}$ indicate the normal and rolling directions, respectively. The insert shows selected area electron diffraction pattern and its schematic representation. 

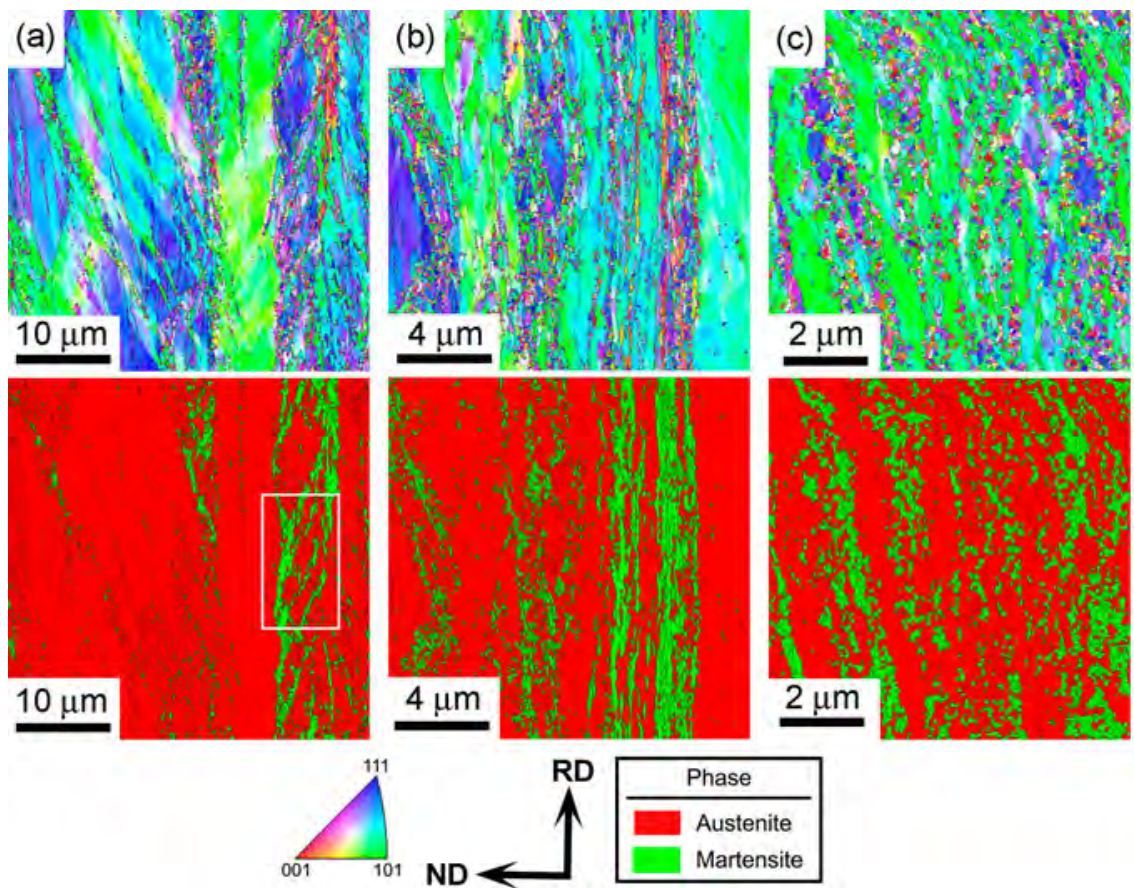

Figure 2. Typical deformation microstructures evolved in a $316 \mathrm{~L}$ stainless steel during cold rolling to total strains of 1 (a), 2 (b), 3 (c). The colours in the upper images correspond to the crystallographic orientations along the normal direction (ND). The colours in the lower images show the austenite/martensite phase distribution. The portion of micro-shear bands selected by the white rectangle in (a) is enlarged in Figure 15.

martensite $[6,26,27]$. Thus, the martensite fraction rapidly increases during cold rolling to strains of $1-2$. The grain flattening and micro-shearing result in the wavy microstructure at large rolling strains (Figures 2 and 3). The largely strained $316 \mathrm{~L}$ steel consists of highly elongated austenite grains separated by nanocrystalline martenisite layers (Figure 2(c)). On the other hand, the largely strained $304 \mathrm{~L}$ steel consists of highly elongated wavy martensite grains interleaved with chains of ultrafine austenite grains (Figure 3(c)). The flattened austenite grains are indicated by green colour in the OIM images in Figures 2 and 3 suggesting a rather strong deformation texture with $<011>\| N D$. In contrast, the flattened martensite grains, which are coloured by red and blue in Figures 2 and 3 , are characterised by a strong deformation texture with $<001>\| N D$ and $<111>\|$ ND.

Figure 4 shows details of micro-shear bands (indicated by arrows in Figure 4), which pass over a grain and shear the nano-twinned lamellae. The micro-shear bands appear as narrow regions (about $500 \mathrm{~nm}$ in thickness) of localised shear. The micro-shear bands consist of alternating elongated martensite and austenite crystallites with the transverse size of about $100 \mathrm{~nm}$. Inside the micro-shear band in Figure 4, the austenite crystallites are oriented with $\langle 111\rangle|| \mathrm{ND}$ and $\langle 011\rangle|| \mathrm{RD}$, while the martensite crystallites are oriented with $\langle 112\rangle|| R D$. Note here that 

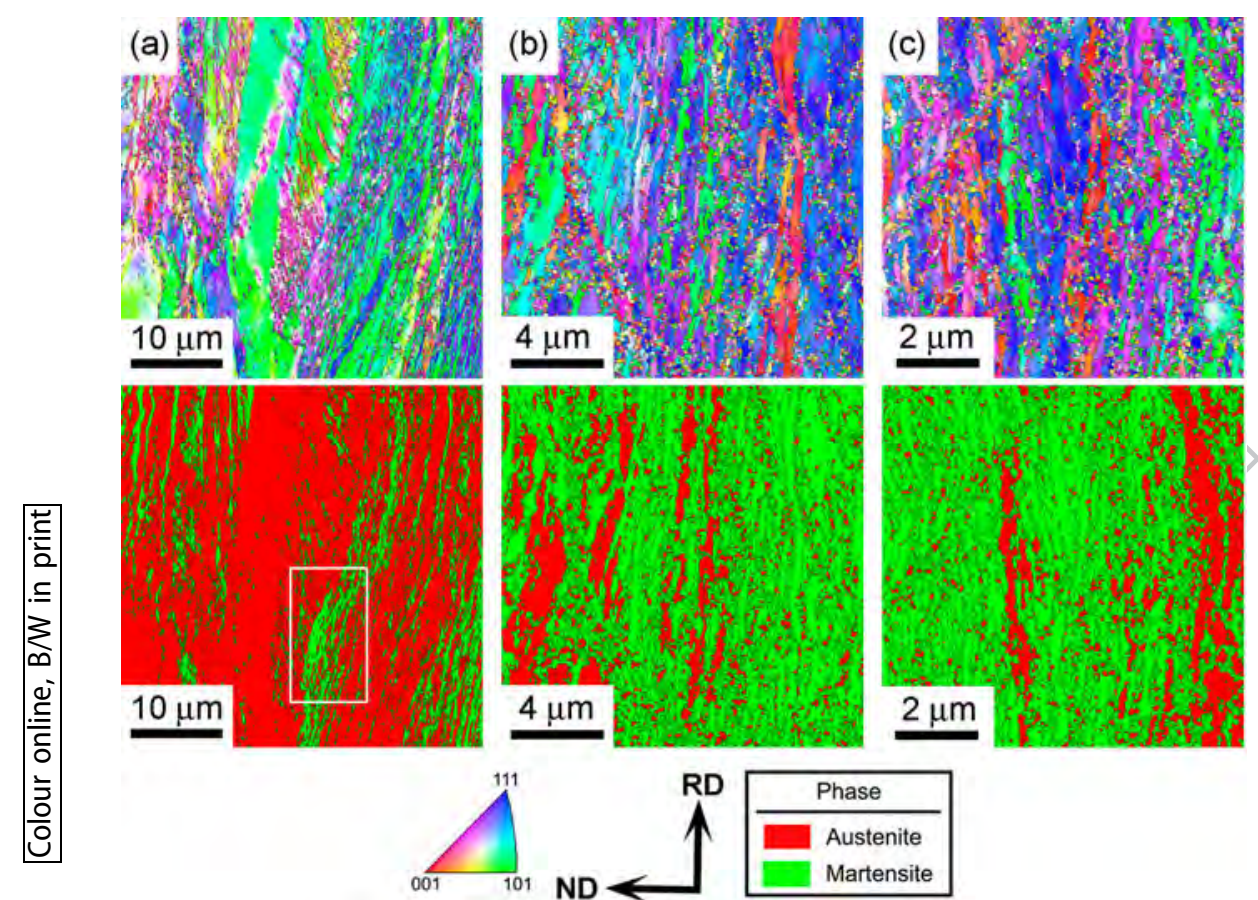

Figure 3. Typical deformation microstructures evolved in a $304 \mathrm{~L}$ stainless steel during cold rolling to total strains of 1 (a), 2 (b), 3 (c). The colours in the upper images correspond to the crystallographic orientations along the normal direction (ND). The colours in the lower images show the austenite/martensite phase distribution. The portion of micro-shear bands selected by the white rectangle in (a) is enlarged in Figure 15.

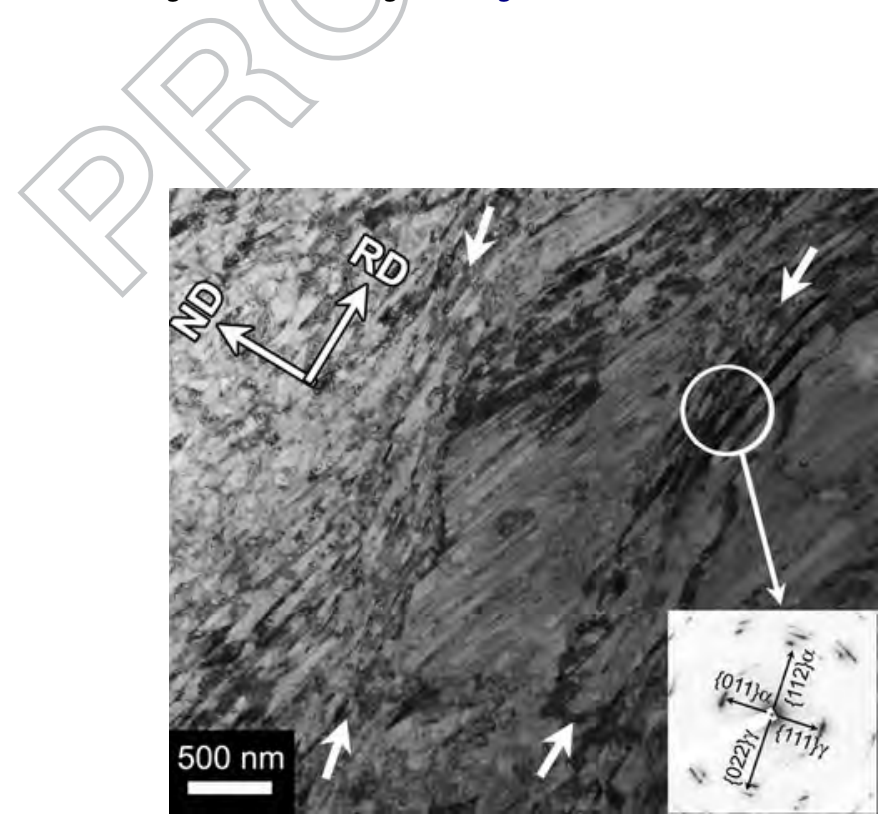

Figure 4. Micro-shear bands (indicated by arrows) in a $304 \mathrm{~L}$ stainless steel after cold rolling to a total strain of 1 . The insert shows selected area electron diffraction pattern obtained from the indicated portion. 
these orientations may belong to so-called $\mathrm{E}(\{111\}<110>)$ and $\mathrm{F}(\{111\}<211>)$ texture components located on the $\gamma$-fibre $[21,22]$. The lamellar-like ultrafine grained microstructures consisting of austenite and martensite grains that develop during cold rolling are shown in Figure 5. The elongated crystallites are bounded by high-angle boundaries, which may result from various variants of martensitic transformation [28]. Not all but most of inter-variant boundaries are high-angle ones [28]. Another origin of the high-angle boundaries is associated with some strain inhomogeneities leading to geometrically-necessary boundaries exhibiting rapidly increasing misorientations during plastic deformation [29]. The electron diffraction patterns obtained by using converged beam technique (Figure 5) suggest that the austenite grains are frequently
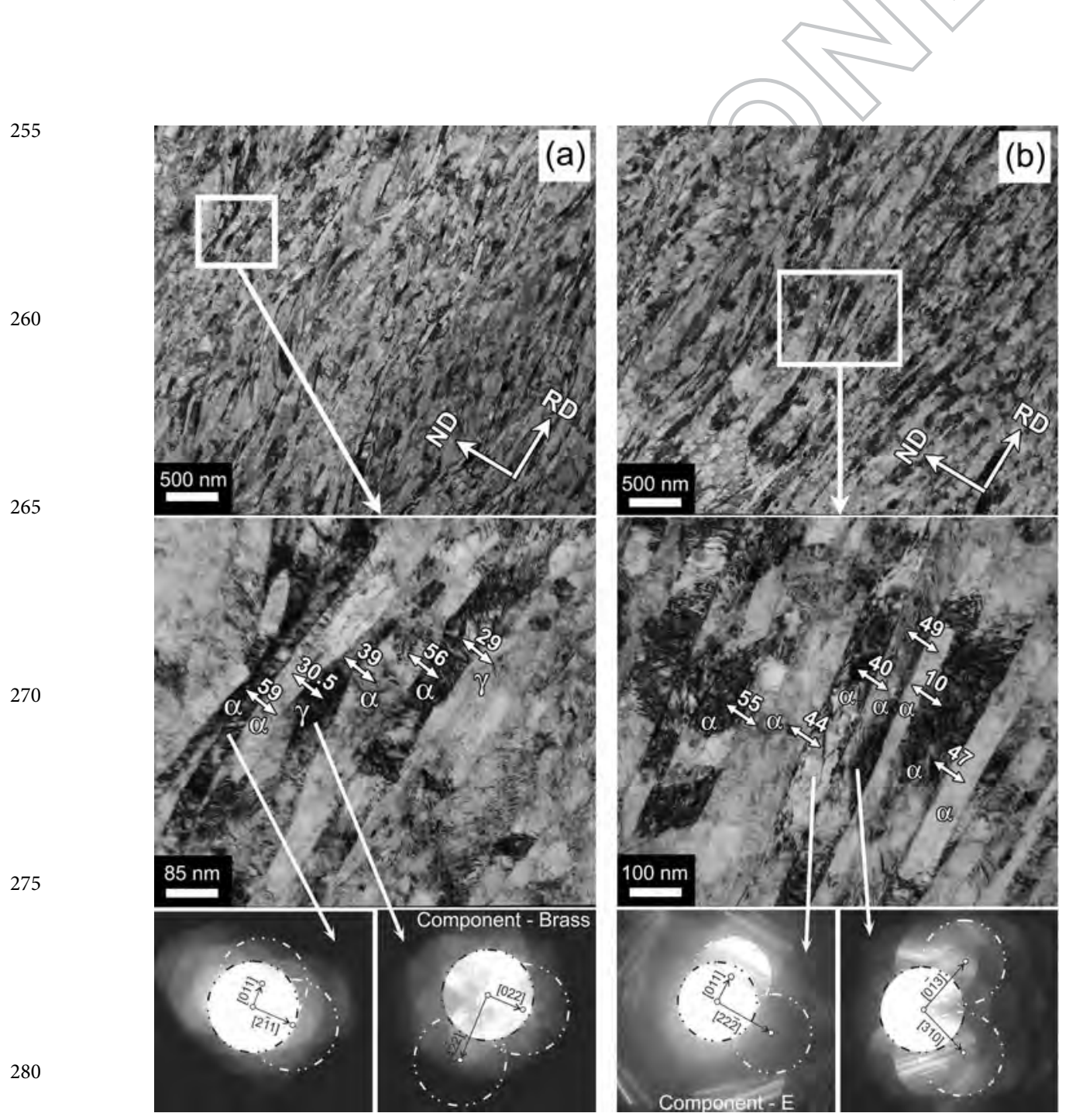

Figure 5. Fine structures in $316 \mathrm{~L}$ (a) and $304 \mathrm{~L}$ (b) stainless steels subjected to cold rolling to a total strain of 2 . The numbers indicate the boundary misorientations in degrees. 
aligned with $\{011\}<211>$ (Brass), whereas the martensite orientations are often close to $\{111\}<110>$.

The strain effect on the volume fraction of martensite is shown in Figure 6. The equilibrium ferrite fractions as calculated by ThermoCalc (TCFE6) are also indicated in Figure 6 by the dashed lines for reference. The present steels are characterised by different austenite stability. The martensitic transformation develops more readily in the $304 \mathrm{~L}$ steel samples. The martensite fraction comprises about 0.15 in the $316 \mathrm{~L}$ steel after cold rolling to a strain of 1.0 , while that in the $304 \mathrm{~L}$ steel is above 0.3 . The strain-induced martensite rapidly develops in the strain range of $0.5<\varepsilon<2.0$. The martensite fraction increases to about 0.2 and 0.7 in the $316 \mathrm{~L}$ and $304 \mathrm{~L}$ steels, respectively, with an increase in the rolling strain to 2.0. Further rolling to large strains is characterised by a gradual decrease in the martensitic transformation activity that leads the martensite fraction to about $0.25(316 \mathrm{~L})$ and $0.8(304 \mathrm{~L})$ at a large total strain of 3 . Olson and Cohen [6] have proposed the following sigmoid relationship for the straininduced martensitic transformation, assuming that shear band intersections are preferential sites for the martensite nucleation.

$$
F_{M}=1-\exp \left(-B(1-\exp (-A \varepsilon))^{n}\right) .
$$

In the present study, $B=0.3, A=1.8, n=4$ and $B=1.7, A=1.2, n=4$ are obtained for the $316 \mathrm{~L}$ and $304 \mathrm{~L}$ steels, respectively. A decrease in the martensitic transformation kinetics at large strains may result from a re-distribution of alloying elements assisted by large strain cold working similar to the phase transformation driven by severe plastic deformation [30].

The grain refinement in the present steels during large strain cold rolling is illustrated in Figure 7, which shows the grain size distributions evolved at different rolling strains. Note here that the area fractions shown in Figure 7

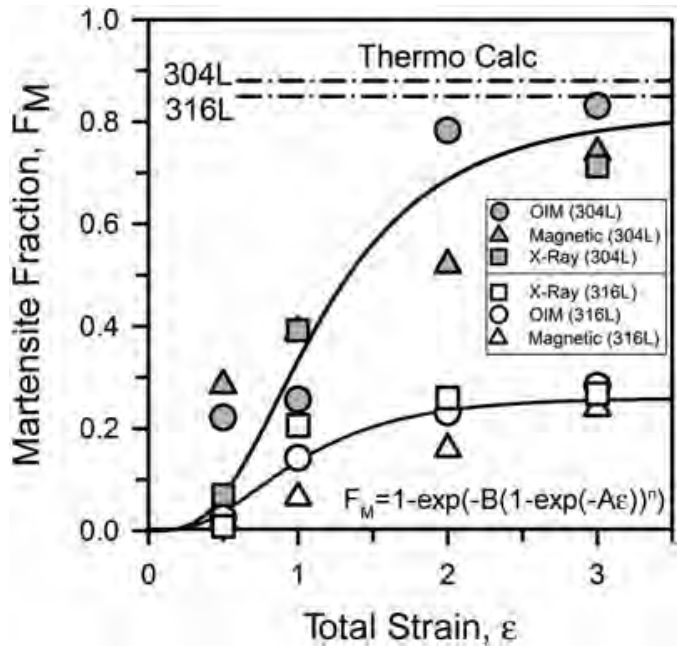

Figure 6. The strain effect on the martensite fraction in $304 \mathrm{~L}$ and $316 \mathrm{~L}$ stainless steels. 

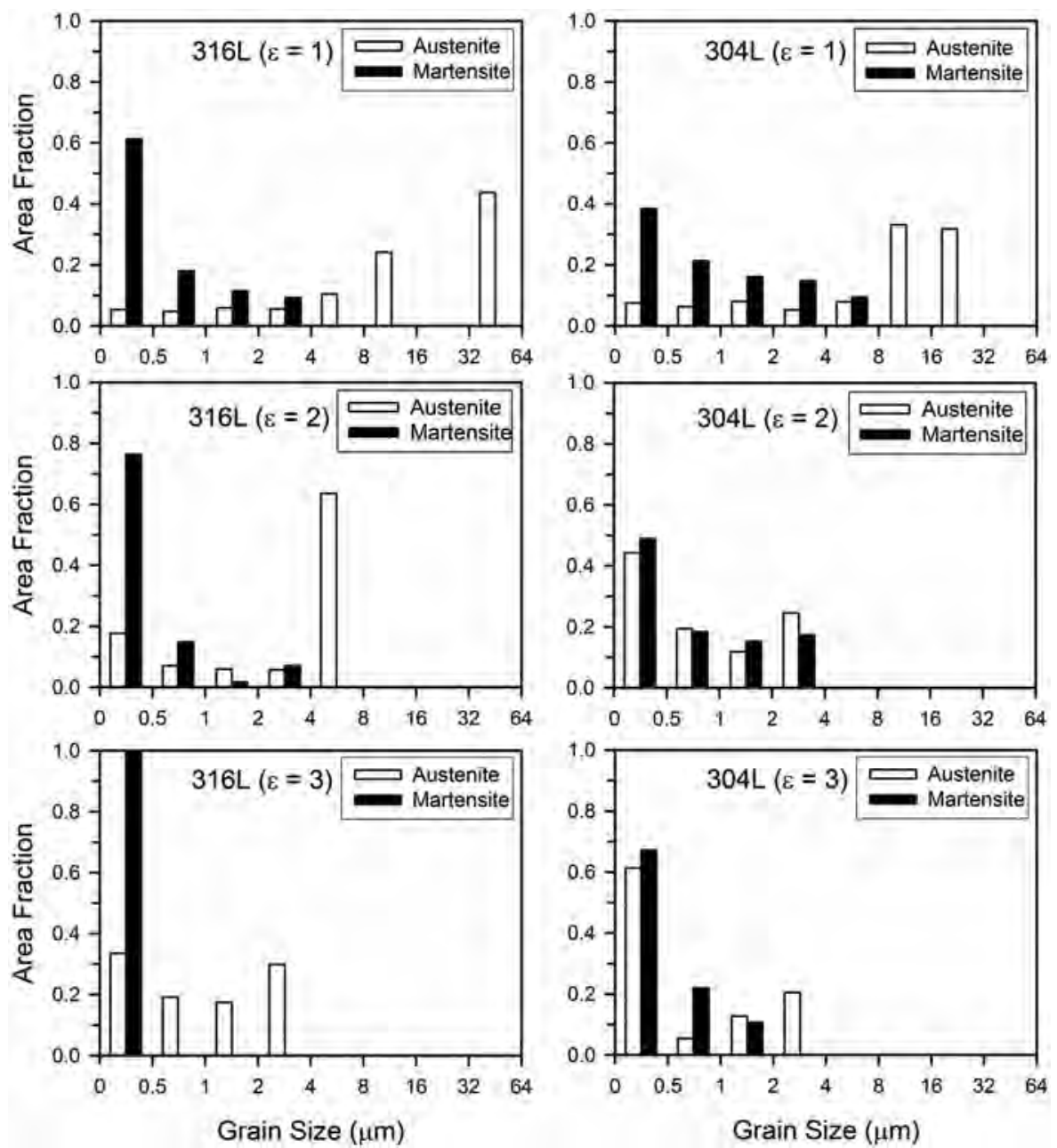

Figure 7. The grain size distribution in $316 \mathrm{~L}$ and $304 \mathrm{~L}$ stainless steels subjected to cold rolling to various total strains $(\varepsilon)$.

are from the EBSP maps. The grain size distributions after relatively small strains of about 1 are characterised by two huge peaks against small (below $0.5 \mu \mathrm{m}$ ) and large (above $8 \mu \mathrm{m}$ ) sizes. The small grain size peak is mainly composed of ultrafine martensite grains, while the large grain size peak consists of austenite. This difference is associated with different kinetics of grain refinement in austenite and martensite. The deformation martensite frequently appears as crystallites with ultrafine dimensions [31]. In contrast, the austenite should experience rather large strains to obtain a large fraction of ultrafine grains [32]. The fraction of ultrafine grains with a size of below $0.5 \mu \mathrm{m}$ progressively increases with increasing the rolling strain, whereas the coarse grains disappear. It should be noted that both austenite and martensite contribute to increasing the fraction of ultrafine grains, although martensite exhibits much faster refinement kinetics than austenite in the $316 \mathrm{~L}$ steel. 
Recently, the grain refinement kinetics during cold to warm working has been suggested to obey a modified Johnson-Mehl-Avrami-Kolmogorov (JMAK) equation similar to kinetics of dynamic recrystallization under conditions of hot working, i.e.

$$
F_{U F G}=1-\exp \left(-k \varepsilon^{n}\right)
$$

where $\mathrm{F}_{\mathrm{UFG}}$ is the fraction of ultrafine grains, $\varepsilon$ is the total strains, $\mathrm{k}$ and $\mathrm{n}$ are constants, which depend on material and processing conditions [33-35]. Taking the area fractions of the grains with a size below $0.5 \mu \mathrm{m}$ as the ultrafine grain fractions $\left(\mathrm{F}_{\mathrm{UFG}}\right)$, the grain refinement kinetics in the present steels are represented in Figure 8, which shows the change in the area fractions of ultrafine grains during cold rolling. Note here that measured ultrafine grain fractions are indicated by open (austenite) and closed (martensite) symbols, whereas those calculated by Eq. 2 using the indicated in Figure 8 parameters are shown by solid lines.

\subsection{Deformation textures}

The orientation distribution functions (ODF) for the samples subjected to cold rolling to various total strains are shown in Figure 9. For reference, ideal orientations of texture components are shown schematically for ODF sections at $\varphi_{2}=$ $0^{\circ}, \varphi_{2}=45^{\circ}$, and $\varphi_{2}=65^{\circ}$ in Figure 10 and defined in Tables 1 and $2[20,36,37]$. Note here that $\mathrm{E}(\{111\}<110>)$ and $\mathrm{F}(\{111\}<211>)$ components are shown for martensite just to illustrate some difference in the texture intensity along the $\gamma$-fibre. Austenite ODF that develop during cold rolling are characterised by an increased pole density around the $\zeta$ - and $\gamma$-fibres, i.e. $\langle 110\rangle \| N D$ and $<111>\| N D$, respectively. The $\gamma$-fibre is stronger in the $316 \mathrm{~L}$ steel, whereas the $\zeta$-fibre is more pronounced in the $304 \mathrm{~L}$ steel. A clear maximum located close to Brass texture component, $\{011\}<211>$, and Goss texture component, $\{011\}<100>$, develops in the both steels at a relatively small strains followed

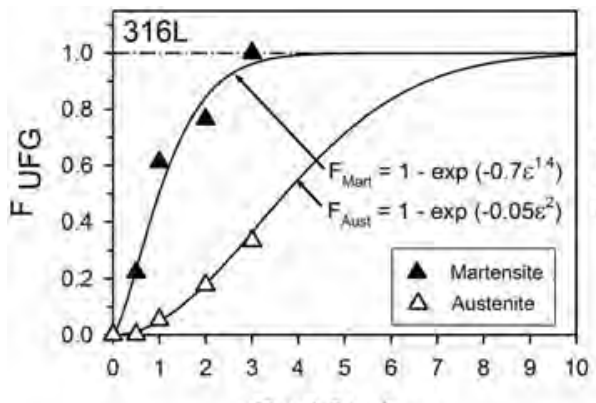

Total Strain, $\varepsilon$

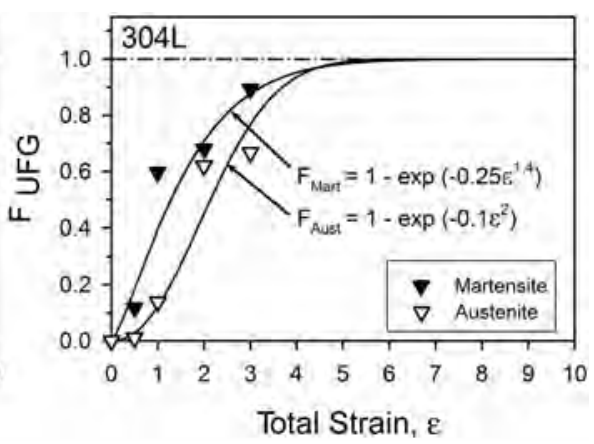

Figure 8. The effect of cold rolling on the fraction of ultrafine grains $\left(F_{U F G}\right)$, i.e. those with a size below $0.5 \mu \mathrm{m}$, in $316 \mathrm{~L}$ and $304 \mathrm{~L}$ stainless steels. 

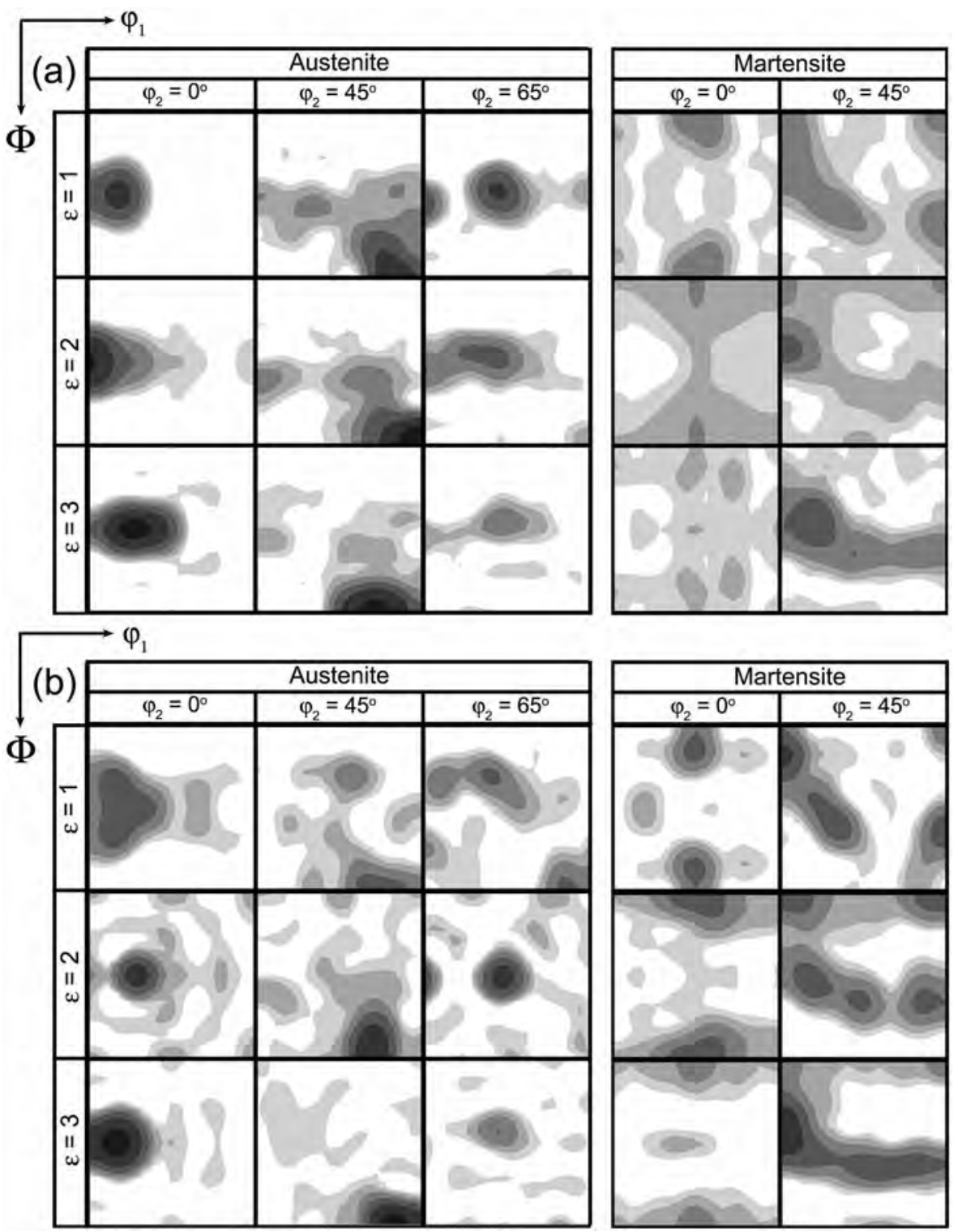

Figure 9. The sections of orientation distribution functions (ODF) at $\varphi_{2}=0^{\circ}, \varphi_{2}=45^{\circ}, \varphi_{2}=65^{\circ}$ for $316 \mathrm{~L}(\mathrm{a})$ and $304 \mathrm{~L}(\mathrm{~b})$ stainless steels cold rolled to total strains $(\varepsilon)$ of $1-3$.

by its strengthening with an increase in the rolling reduction. The $\gamma$-fibre with maximums corresponding to $\mathrm{E}(\{111\}<110>)$ and $\mathrm{F}(\{111\}<211>)$ texture components rapidly develops at strains of $1-2$. Then, the $\gamma$-fibre gradually weakens, especially, in the $304 \mathrm{~L}$ steel with increasing the total strain.

The texture of deformation martensite is characterised by the development of $\eta$ - and $\gamma$-fibres, i.e. $<100>\| N D$ and $<111>\| N D$, respectively. The $\eta$-fibre with maximums corresponding to the rotated cube component, $\{001\}<110>$, develops at strains of $1_{-} 2$. The $\gamma$-fibre intensity gradually increases during cold rolling, 

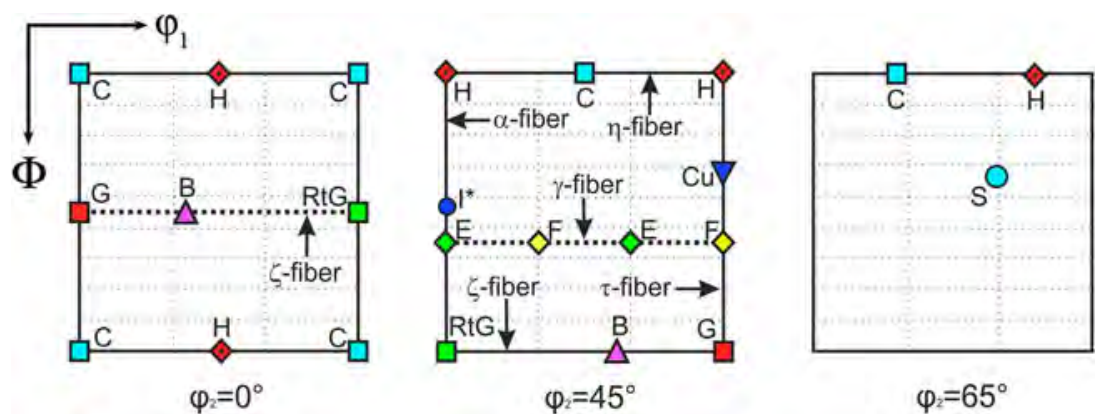

$\varphi_{2}=65^{\circ}$

Figure 10. Characteristic texture components $[20,36,37]$.

Table 1. Definition of texture components in austenite.

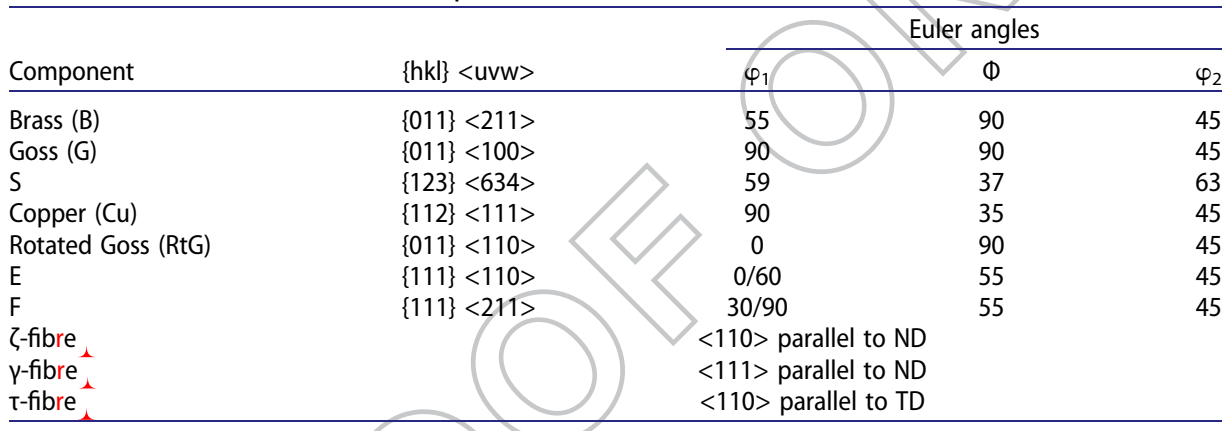

Table 2. Definition of texture components in martensite.

\begin{tabular}{|c|c|c|c|c|}
\hline \multirow[b]{2}{*}{ Component } & $\multirow[b]{2}{*}{$ hkl }$<$ uvw $>$ & \multicolumn{3}{|c|}{ Euler angles } \\
\hline & & $\varphi_{1}$ & $\Phi$ & $\varphi_{2}$ \\
\hline Cube (C) & $\{001\}<100\rangle$ & 45 & 0 & 45 \\
\hline Rotated c & $\{001\}<110>$ & $0 / 90$ & 0 & 45 \\
\hline $1^{*}$ & $\{223\}<110>$ & 0 & 43 & 45 \\
\hline $\mathrm{E}$ & $\{111\}<110>$ & $0 / 60$ & 55 & 45 \\
\hline $\mathrm{F}$ & $\{111\}<211>$ & $30 / 90$ & 55 & 45 \\
\hline Goss (G) & $\{110\}<001>$ & 90 & 90 & 45 \\
\hline$\eta$-fibre & & $<001>$ parallel to ND & & \\
\hline$a$-fibre & & $<110>$ parallel to RD & & \\
\hline$\gamma$-fibre & & $<111>$ parallel to ND & & \\
\hline
\end{tabular}

leading to the sharp fibre texture with nearly the same pole density along the fibre at a large strain of 3. Both the $\eta$ - and $\gamma$-fibres are more intense in the $304 \mathrm{~L}$ steel than in the $316 \mathrm{~L}$ one. The deformation martensite is characterised by the development of strong $I^{*}$ texture component, $\{223\}<110>$, which is also more intense in the $304 \mathrm{~L}$ steel. The difference in the martensite texture intensity between the $304 \mathrm{~L}$ and $316 \mathrm{~L}$ steels can be associated with the different volume fractions of the deformation martensite in these steels.

The effect of cold rolling on the development of characteristic texture components in austenite and martensite is quantitatively shown in Figure 11. The 

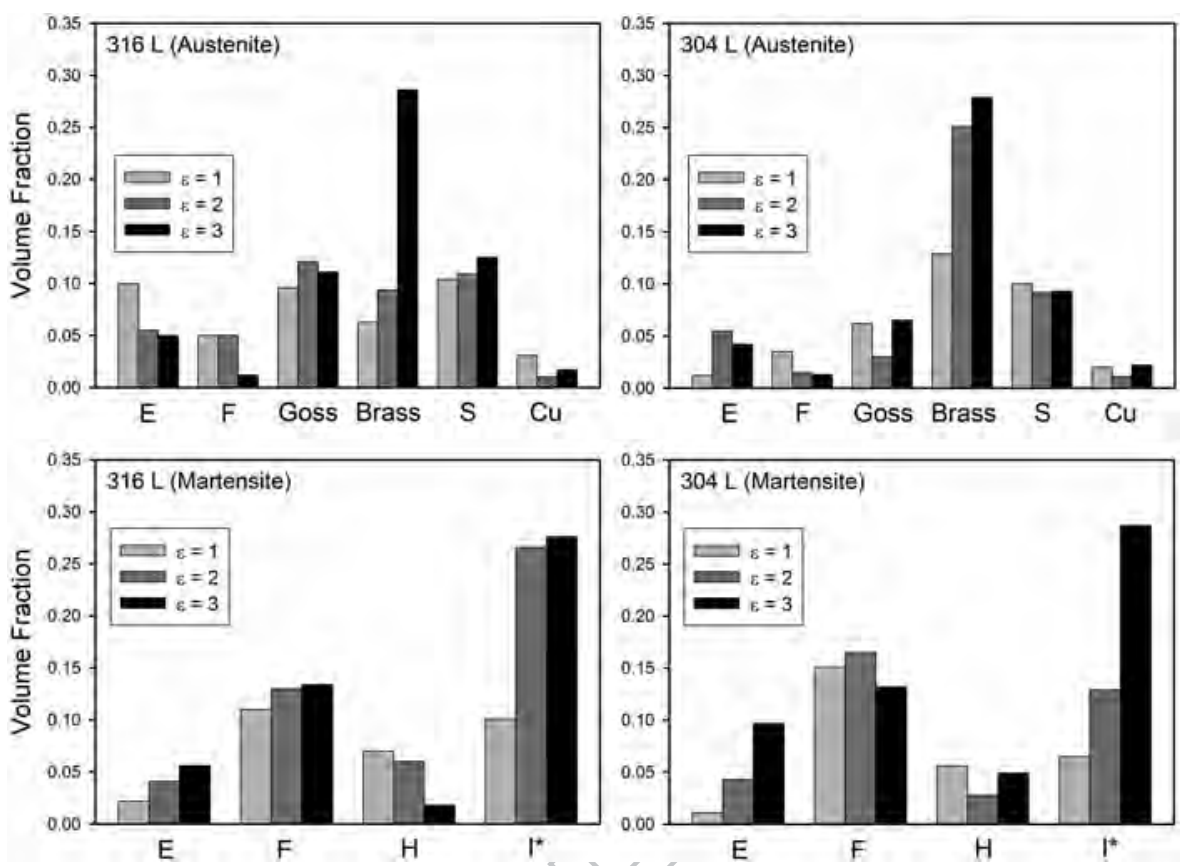

Figure 11. Fractions of the main texture components evolved in $316 \mathrm{~L}$ and $304 \mathrm{~L}$ stainless steels by cold rolling to different strains.

austenite in the $316 \mathrm{~L}$ steel is characterised by the development of E, F, Goss, Brass and $S(\{123\}<634>)$ components with almost the same fractions at small to moderate strains of $1-2$. An increase in the rolling strain to 3 is accompanied with a drastic increase in the Brass component, while those belonging to $\gamma$-fibre, i.e. E and F components, weaken. In contrast, the Brass component fraction in the $304 \mathrm{~L}$ steel exceeds other textural components developed in a wide range of total strains from 1 to 3 . This difference can be attributed to the difference in SFE. Commonly, a decrease in SFE promotes the development of Brass component in fcc-metals/alloys during cold rolling [38,39]. The deformation martensite in the both steels exhibits similar distribution of texture component fraction with a predominance of $\mathrm{F}(\{111\}<211>)$ and $\left.\mathrm{I}^{*}(223\}<110>\right)$ components, although the latter develops faster in the $316 \mathrm{~L}$ steel.

\subsection{Tensile properties}

The tensile stress-elongation curves for the $304 \mathrm{~L}$ and $316 \mathrm{~L}$ stainless steels subjected to cold rolling to different total strains are shown in Figure 12. The tensile behaviour of the both cold rolled steels is commonly characterised by a rapid increase in the flow stress to a peak stress at relatively small strains corresponding to quite small uniform elongation of $1-2 \%$ followed by necking leading to a gradual decrease in the flow stress until fracture. The tensile strength increases, 

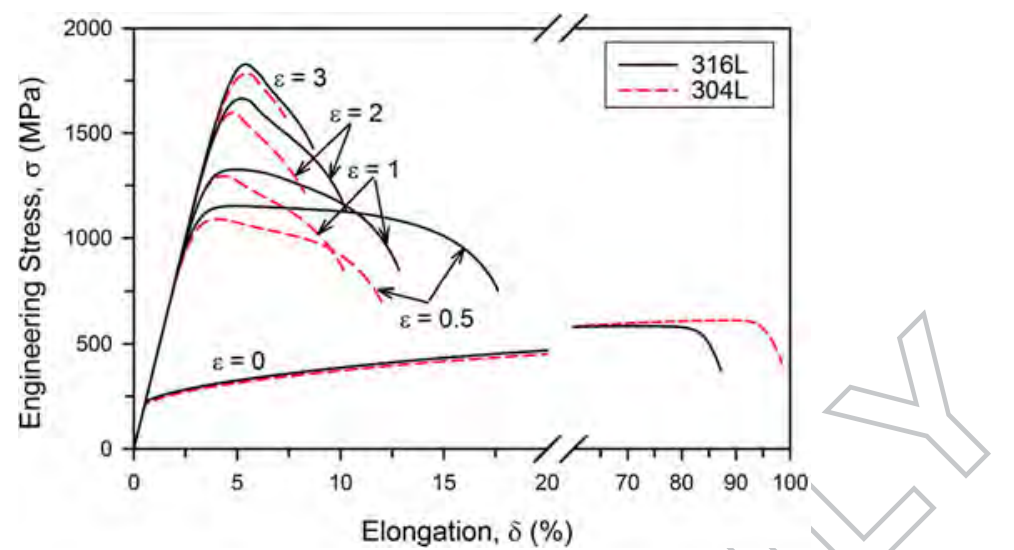

Figure 12. Tensile stress-elongation curves for $316 \mathrm{~L}$ and $304 \mathrm{~L}$ stainless steel samples processed by cold rolling to different total strains $(\varepsilon)$.

while the total elongation decreases with an increase in the previous rolling strain. Cold rolling to a strain of 3 results in significant increase in the ultimate tensile strength from about $600 \mathrm{MPa}$ in the initial annealed conditions to $1785 \mathrm{MPa}$ and $1830 \mathrm{MPa}$ in the $304 \mathrm{~L}$ and $316 \mathrm{~L}$ steels, respectively, whereas total elongation decreases to approx. $5 \%$ in the both steels. The trouble with ductility can be remedied by an appropriate heat treatment, although the strengthening should be partially lost after annealing.

The $316 \mathrm{~L}$ steel samples exhibit higher strength as compared to the $304 \mathrm{~L}$ steel samples after cold rolling to the same strain levels, although the initial annealed samples were characterised by almost the same strength. It should also be noted that the cold rolled $316 \mathrm{~L}$ steel samples exhibit remarkably higher tensile flow stresses in the necking strain range, i.e. after the peak-stress, leading to larger total elongations than those in the $304 \mathrm{~L}$ steel samples. This suggests that in spite of higher SFE in the $316 \mathrm{~L}$ steel, this steel is more susceptible to work hardening than $304 \mathrm{~L}$ one during both the cold rolling and the subsequent tensile tests.

\section{Discussion}

\subsection{Grain refinement}

The grain refinement during large strain cold working has been discussed in terms of grain subdivision or continuous dynamic recrystallization that implies the strain-induced continuous reactions as the mechanisms of new ultrafine grain development [40-44]. Namely, the development of new grains is closely associated with the appearance of strain-induced grain boundaries.

560 The present results suggest that the new ultrafine grains appear heterogeneously in the austenitic stainless steels subjected to cold working, although the highangle grain boundaries gradually evolve in continuous manner during straining. The new austenite grains readily develop in the places of high structural 
heterogeneity, which results from deformation twinning and micro-shear banding, followed by ultrafine grain propagation throughout the sample as the density of structural heterogeneities increases during plastic working. Also, the strain-induced martensite consisting of ultrafine crystallites develops heterogeneously at micro-shear bands/twins and their intersections, and the number of ultrafine martensite grains progressively increases with increasing the density of micro-shear bands/twins during deformation. The heterogeneous grain refinement during cold rolling of the austenitic stainless steels is illustrated in Figure 7, which shows a gradual increase in the fraction of ultrafine grains while the coarse grain fraction decreases.

The final grain size, which can be attained at sufficiently large strains, has been shown to depend on the processing conditions in a wide range of deformation temperatures and strain rates from cold to hot working [44]. Figure 13 shows the change in the size of ultrafine grains in the stainless steels during cold rolling, counting austenite and martensite grains all together. It is clearly seen that the size of the ultrafine grains, i.e. those with a size below 0.5 $\mu \mathrm{m}$ as selected in Figures 7 and 8, tends to approach $100 \mathrm{~nm}$ with an increase in the total strain. Assuming that new grains with a size of $D_{U F G}$ evolve in a microstructure with an initial grain size of $D_{0}$, the mean grain size during the grain refinement process can be expressed as follows [45].

$$
D_{\varepsilon}=\left(\left(1-F_{U F G}\right) D_{0}^{-2}+F_{U F G} D_{U F G}^{-2}\right)^{-0.5} .
$$

Substituting the fraction of ultrafine grains $\left(\mathrm{F}_{\mathrm{UFG}}\right)$ from Eq. 2, the mean grain size reads

$$
D_{\varepsilon}=\widehat{D}_{U F G}\left(1+\left(\left(D_{U F G} / D_{0}\right)^{2}-1\right) \exp \left(-k \varepsilon^{n}\right)\right)^{-0.5} \text {. }
$$

Taking $\mathrm{D}_{\mathrm{UFG}}=100 \mathrm{~nm}$ and ignoring $\left(\mathrm{D}_{\mathrm{UFG}} / \mathrm{D}_{0}\right)^{2}$ because $\mathrm{D}_{\mathrm{UFG}}<<\mathrm{D}_{0}$ (in the present study $\mathrm{D}_{\mathrm{UFG}} / \mathrm{D}_{0}$ is about 0.005 ), the change in the mean grain size as calculated by Eq. 4 is shown in Figure 14 (dotted lines) along with the experimental values of austenite and martensite grain sizes. Note here that $\mathrm{k}$ and $\mathrm{n}$ are used in Eq. 4 with their values indicated in Figure 8. Some difference between the calculated and measured grain sizes at relatively small strains is caused by smaller $\mathrm{D}_{\mathrm{UFG}}=100 \mathrm{~nm}$ used for a sake of simplicity for calculation by Eq. 4 as compared 595 to the mean $\mathrm{D}_{\mathrm{UFG}}$ (s. Figure 13). On the other hand, the grain sizes calculated by Eq. 4 match well the experimental ones at rather large strains. The present relationships (Figure 14) suggest faster kinetics of the overall grain refinement in the $304 \mathrm{~L}$ steel as compared to $316 \mathrm{~L}$ one. This is attributed to the different martensitic transformation kinetics in these steels. The $304 \mathrm{~L}$ steel samples sub600 jected to cold rolling exhibit larger fractions of deformation martensite than the samples of $316 \mathrm{~L}$ steel processed to the same cold strain levels (Figure 6). The rapid development of ultrafine grained martensite, therefore, leads to the rapid grain refinement in the $304 \mathrm{~L}$ steel samples. 


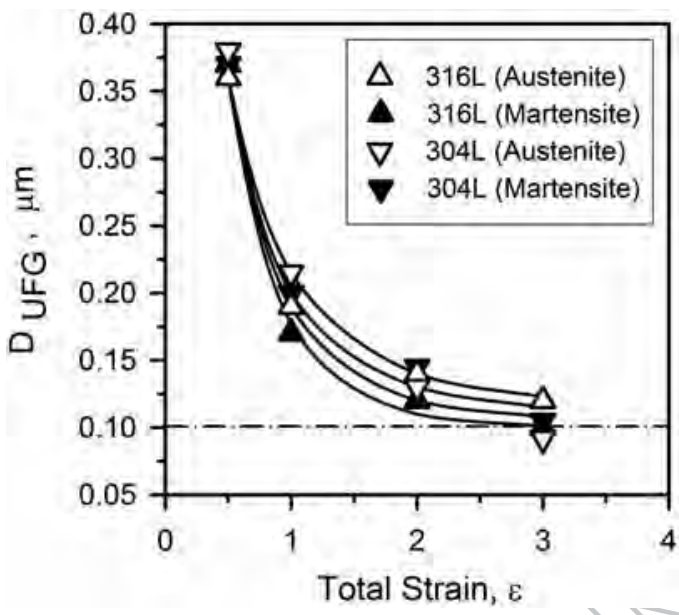

Figure 13. The strain effect on the size of ultrafine grains ( $D_{\mathrm{UFG}}$ ), i.e. those with a size below 0.5 $\mu \mathrm{m}$, in $316 \mathrm{~L}$ and $304 \mathrm{~L}$ stainless steels subjected to cold rolling.
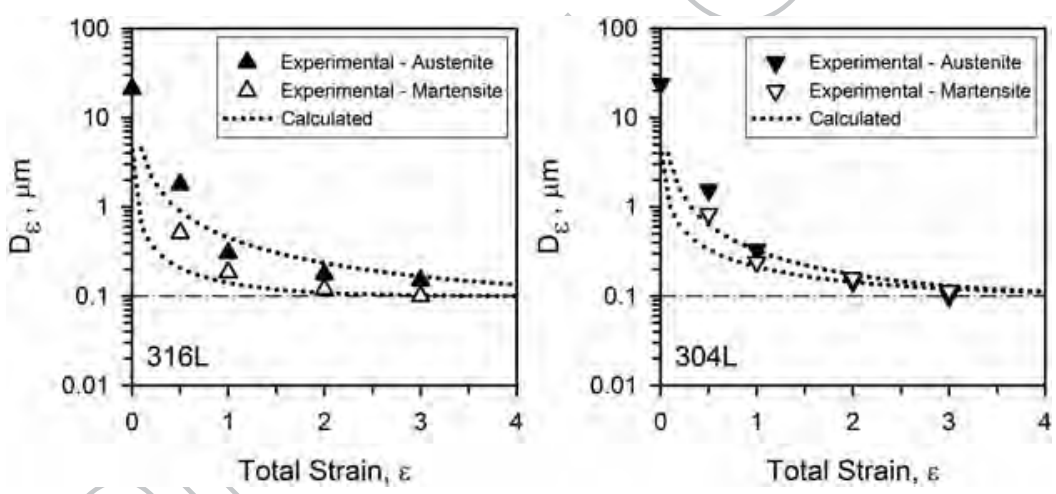

Figure 14. The strain effect on the mean grain size in $316 \mathrm{~L}$ and $304 \mathrm{~L}$ stainless steels subjected to cold rolling.

It should be noted that similar approach to evaluate the grain size during large strain cold working has provided a good correspondence between the experimental and calculated grain sizes in a copper alloy processed by equal channel angular pressing [46]. It is worth noting that Eq. 4 was derived assuming heterogeneous manner of the microstructure evolution, which has been considered as a common feature of continuous dynamic recrystallization in metals and alloys under conditions of warm working. Thus, the speculation above including Eqs. 2-4 can be used to predict the grain refinement in various metallic materials subjected to large strain cold-to warm working.

\subsection{Texture e evolution}

The textures that develop in the steels during cold rolling are closely related to the microstructural changes, which are characterised by the development of 
deformation twins at small strains followed by micro-shear banding and martensitic transformation. Generally, the rolling textures in fcc-metals/alloys consist of an orientation tube with a skeleton line stretching along the $\beta$-fibre, $<110>$ tilted by $60^{\circ}$ from ND to $\mathrm{RD}$, from the Copper texture component, $\{112\}<111>$, over the $S$ component, $\{123\}<634>$, to the Brass component, $\{011\}<211>$, followed by the $\zeta$-fibre $[46,47]$. The latter consists of all orientations lying between the Goss component, $\{011\}<100>$, and the Brass component and defined by $\langle 110\rangle$ being parallel to ND. The orientation density along the tube ( $\beta$-fibre) depends on concurrent operations of dislocation slip, deformation twinning and shear banding. These contributions, in turn, depend on SFE. A decrease in SFE promotes the development of deformation twinning followed by shear banding and, therefore, leads to a reduction of the Copper component intensity, while the fraction of Brass component increases [39,46-48].

The texture of deformation austenite in the present steels is characterised by the rapid development of rather strong Brass and $S$ components, which are typical of cold rolled low-to-moderate SFE fcc-materials susceptible to deformation twinning and shear banding [38,49-52]. In addition, the E and F components develop at moderate rolling strains of about 1 , when the micro-shear banding is enhanced. Typical examples of various texture components in deformation austenite are shown in Figure 15, which represents enlarged images of the selected portions in Figures 2(a) and 3(a). The major components are Goss, Brass and S; and their relative fractions depend on SFE in the studied steels. The Goss component evolves in relatively large remnants of original flattened grains (s. the red portions in Figure 15) that may be associated with their stable orientation during plate rolling. In contrast, the Brass and S components develop in the grains with high density of micro-shear bands, when the rather large portions with Brass and $\mathrm{S}$ orientations (purple and blue in Figure 15) are interleaved with the ultrafine grains/subgrains belonging to $\mathrm{E}$ and $\mathrm{F}$ components (green and yellow in Figure 15). The micro-shear banding in low SFE austenite during cold rolling has been shown to result in the development of $\mathrm{E}$ and $\mathrm{F}$ components [24]. In the present steels, an apparent decrease in the fraction of $\mathrm{E}$ and $\mathrm{F}$ components during rolling to large total strains can be caused by the martensitic transformation, which develops in the micro-shear bands and, therefore, decreases the shear-band-related orientations in austenite.

The strain-induced martensite is characterised by the development of a strong $\gamma$-fibre with a maximum at $\{111\}<211>$ followed by an increase in $\mathrm{I}^{*}$ $(\{223\}<110>)$ component (Figures 9 and 11). Similar textures have been frequently observed in body centred cubic metals after large strain cold rolling $[37,53,54]$. The development of strong $I^{\star}(\{223\}<110>)$ component has been attributed to the main operative slip systems of $\{011\}<111>$-type [53]. It should be noted that the martensite textures in the present $316 \mathrm{~L}$ and $304 \mathrm{~L}$ steels are almost the same. Somewhat stronger martensite texture in the $304 \mathrm{~L}$ 

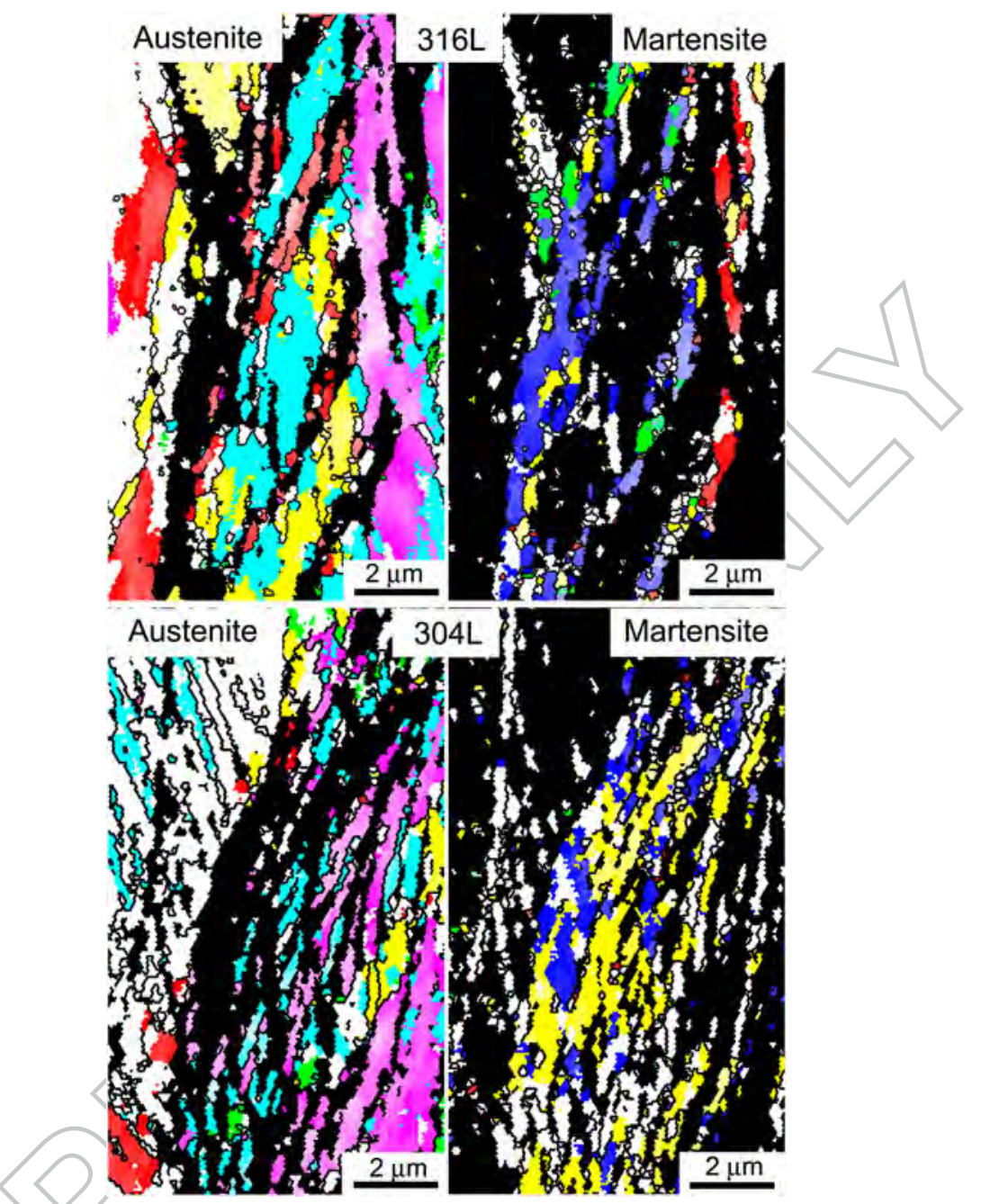

Figure 15. Orientation maps of austenite and martensite in $316 \mathrm{~L}$ and $304 \mathrm{~L}$ stainless steels after cold rolling to a total strain of 1 . Different texture components are indicated by different colours, i.e. Brass $(\{011\}<211>)$ - purple, Goss $(\{011\}<100>)$ - red, $S(\{123\}<634>)$ - blue, E $(\{111\}<100>)$ - green, $F(\{111\}<211>)$ - yellow in austenite and Rotated cube $(\{001\}<110>)$ - red, $F$ $(\{111\}<211>)$ - yellow, $I^{*}(\{223\}<110>)$ - dark blue, $E(\{111\}<110>)$ - green in martensite.

steel may be associated with larger martensite fraction in this steel. The microshear bands serve as preferential nucleation sites for the strain-induced martensite. It is clearly seen in Figure 15 that most of the martensite in the micro-shear bands exhibits either $\mathrm{F}(\{111\}<211>)$ or $\mathrm{I}^{*}(\{223\}<110>)$ orientations.

The strain-induced martensite should inherit the orientation of deformation austenite. Assuming that the austenite-to-martensite transformation takes place by a shear mechanism, the developing martensite orientations should generally follow Kurdjumov-Sachs or Nishiyama-Wasserman orientation relationships $[55,56]$. Note here that both of them predict similar orientations, with a difference of about $5^{\circ}$ [57]. The deformation austenite in the cold rolled samples is 
characterised by strong Brass, Goss and S components (Figure 11). Figure 16 shows the martensite orientations, which should result from Brass, Goss and S oriented austenite in accordance to Kurdjumov-Sachs (24 variants) or Nishiyama-Wasserman (12 variants) orientation relationships. It is clearly seen in Figure 16 that most of the transformed martensite orientations are located close to the $\gamma$-fibre. It is worth noting that the martensite transformed from Brass oriented austenite is concentrated close to $F(\{111\}<211>)$ component. Therefore, the transformed martensite is characterised by the large fraction of $\mathrm{F}(\{111\}<211>)$ component, which is dominant at relatively small strains, followed by gradual increase in the $\mathrm{I}^{*}(\{223\}<110>)$ component with an increase in the total strains (Figure 11).

\subsection{Deformation strengthening}

The strengthening during cold working is commonly attributed to an increase in the density of dislocations including those in dislocation subboundaries (dislocation strengthening) and grain boundaries including strain-induced grain boundaries (grain size strengthening) $[27,32,58]$. Both the dislocation and grain size strengthening were combined in a modified Hall-Petch-type relationship, which demonstrated good agreement with experiments [27,32,58]. The trouble with this approach is that the dislocation density is hard to be measured accurately. Recently, the dislocation density in cold worked metals and alloys has been shown to correlate with the density of grain boundaries, leading to a linear dependence between the dislocation strengthening and the grain size strengthening [59]. Thus, the strengthening by cold working can be evaluated by using either dislocation density or grain size. The latter has a certain advantage. In contrast to the dislocation density, the grain size (or grain boundary spacing)

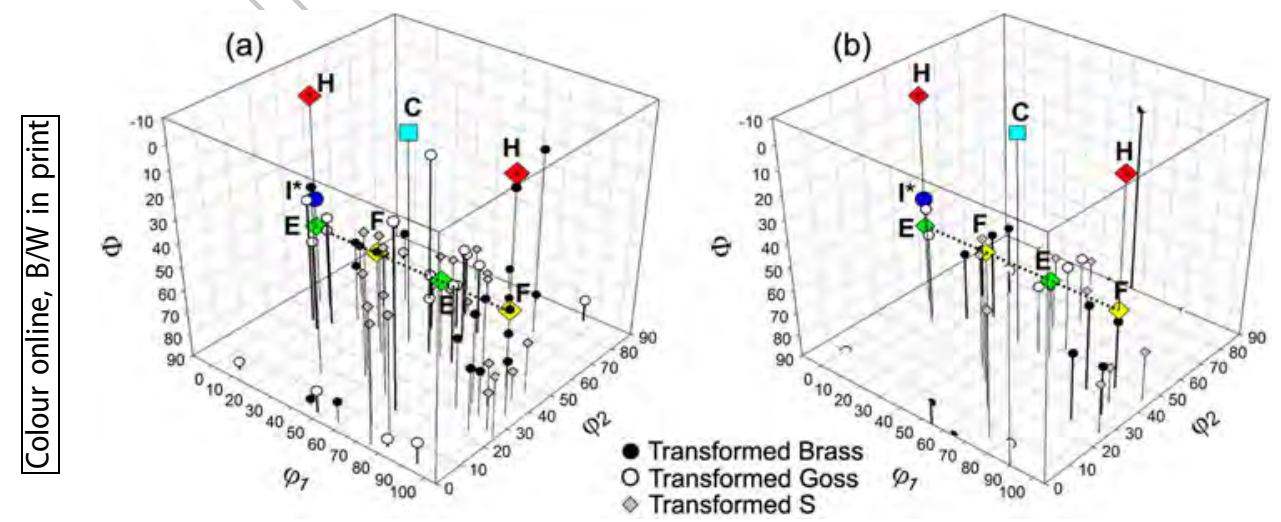

Figure 16. Orientations of martensite transformed from austenite with Brass, Goss and S orientations through Kurdjumov-Sachs (a) or Nishiyama-Wassermann (b) orientation relationships. Some characteristic orientations on $\varphi_{2}=45^{\circ}$ section are also indicated for reference. The dashed lines indicate $\gamma$-fibre. 
can be easily measured much more correctly. This approach has been successfully applied for the yield strength evaluation in stainless steels subjected to warm to hot working, using the relationship between the dynamically recrystallized grain size and the dislocation density [60].

Therefore, the yield strength of the present steel samples after cold rolling to various strains can be expressed using the grain sizes in austenite $\left(D_{A}\right)$ and martensite $\left(\mathrm{D}_{\mathrm{M}}\right)$ as follows.

$$
\sigma_{0.2}=F_{A}\left(\sigma_{0 A}+k_{\varepsilon A} D_{A}^{-0.5}\right)+F_{M}\left(\sigma_{0 M}+k_{\varepsilon M} D_{M}^{-0.5}\right),
$$

where $\mathrm{F}_{\mathrm{A}}=1-\mathrm{F}_{\mathrm{M}}$ is the austenite fraction, $\sigma_{0 \mathrm{~A}}$ and $\sigma_{0 \mathrm{M}}$ are the strength of austenite and martensite, respectively, with infinite grain size, $k_{\varepsilon A}$ and $k_{\varepsilon M}$ are strengthening factors for austenite and martensite, respectively. The relationship between the strengthening and grain sizes of austenite and martensite for the present steels are shown in Figure 17, taking $\sigma_{0 \mathrm{~A}}=180 \mathrm{MPa}$ and $\sigma_{0 \mathrm{M}}=$ $120 \mathrm{MPa}$ [27]. The experimental data points in Figure $17 \mathrm{can}$ be interpolated by a plane function with $\mathrm{k}_{\varepsilon \mathrm{A}}=635 \mathrm{MPa} \mu \mathrm{m}^{0.5}$ and $\mathrm{k}_{\varepsilon \mathrm{M}}=470 \mathrm{MPa} \mu \mathrm{m}^{0.5}$. Note here, apparently large values of strengthening factors as compared to other studies on Hall-Petch strengthening [61] are associated with the dislocation strengthening contributions, which are incorporated in Eq. 5 as portions of grain size strengthening. Taking, the grain sizes from Eq. 4, the flow stresses of the cold rolled steel samples can be expressed by a function of total strain as shown in Figure 18, where $k_{\varepsilon A}=745 \mathrm{MPa} \mu \mathrm{m}^{0.5}$ and $\mathrm{k}_{\varepsilon \mathrm{M}}=510 \mathrm{MPa} \mu \mathrm{m}^{0.5}$ are used as strengthening factors. The higher value of the strengthening factor for austenite implies higher rolling strengthening for steel with larger austenite fraction, i.e. for the $316 \mathrm{~L}$ steel in the present study. This is associated with a high austenite susceptibility to work hardening. The work hardening has been considered as the main contributor to the overall strength of the cold rolled stainless

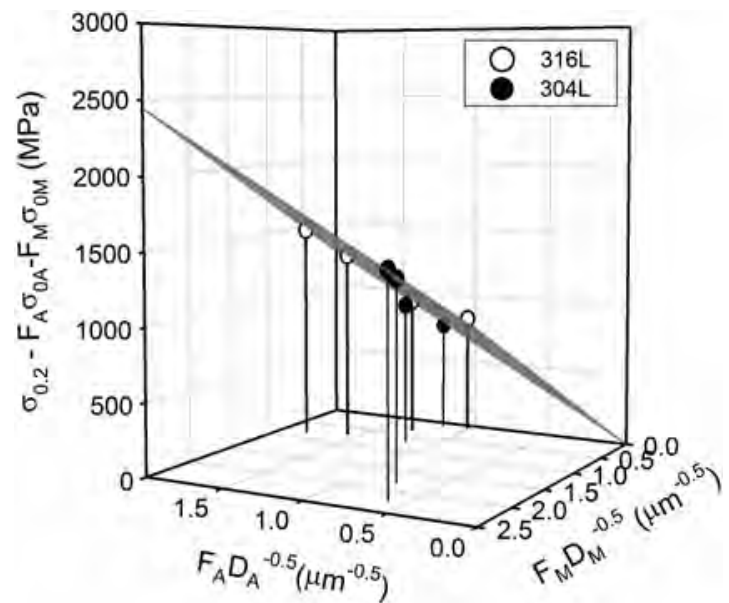

Figure 17. Relationship between the yield strength and the grain sizes of austenite and martensite in $316 \mathrm{~L}$ and $304 \mathrm{~L}$ stainless steels subjected to cold rolling. 


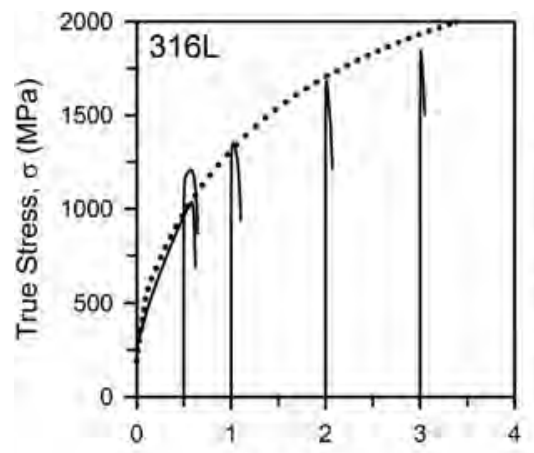

Total Strain, $E$

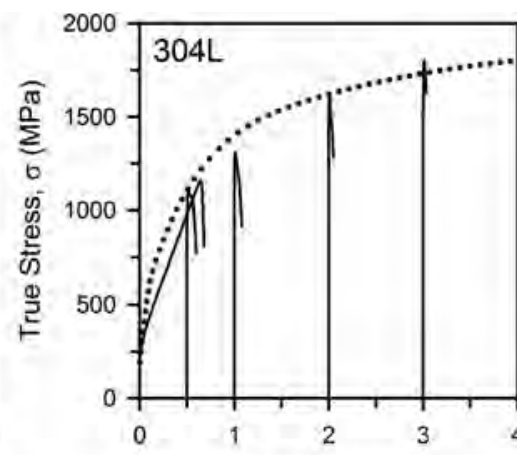

Total Strain, $\varepsilon$

Figure 18. The strain effect on the strength of $316 \mathrm{~L}$ and $304 \mathrm{~L}$ stainless steels subjected to cold rolling. The solid lines represent the experimental stress-strain curves and the dotted lines correspond to those calculated by Eq. 5 .

steels [27,32]. Similar results on the austenite and martensite strengthening have been obtained in other studies on stainless steels subjected to large strain cold rolling, when the deformation martensite itself has not led to any additional strengthening [10,62]. Good agreement between the experimental and calculated stresses in Figure 18 validates the proposed approach, which can be used to predict the strengthening of meta-stable austenitic steels during cold rolling.

\section{Conclusions}

The deformation microstructures/textures and mechanical properties of $304 \mathrm{~L} /$ 316 L-type austenitic stainless steels subjected to large strain plate rolling at ambient temperature were studied. The main results can be summarised as follows.

(1) Cold rolling is accompanied by deformation twinning, micro-shear banding and martensitic transformation. The $316 \mathrm{~L}$ steel samples are more stable against martensitic transformation than $304 \mathrm{~L}$ steel samples. The martensite fraction comprises 0.25 and 0.8 in the $316 \mathrm{~L}$ and $304 \mathrm{~L}$ steels, respectively, after cold rolling to a total strain of 3 .

(2) Cold rolling results in rapid grain refinement, which is assisted by grain subdivision owing to deformation twinning, micro-shear banding and martensitic transformation. The fraction of ultrafine grains with a size of below 0.5 $\mu \mathrm{m}$ can be expressed by a modified Johnson-Mehl-Avrami-Kolmogorov equation. The fractions of ultrafine austenite and martensite grains in the $304 \mathrm{~L}$ steel samples are about 0.6 after total strain of 3 . In contrast, the fractions of ultrafine grained austenite and martensite in the $316 \mathrm{~L}$ steel samples comprise 0.4 and almost 1.0 , respectively, after straining to 3 . The strain dependence of the mean grain size can be expressed as $D_{\varepsilon}=D_{U F G}(1-$ $\left.\exp \left(-k \varepsilon^{n}\right)\right)_{\perp}^{-0.5}$, where $D_{U F G}$ is the final size of ultrafine grains, $k$ and $n$ are constants depending on material and processing conditions. 
(3) The austenite deformation textures are characterised by the development of Brass $(\{011\}<211>)$, Goss $(\{011\}<100>)$ and $S(\{123\}<634>)$ components with nearly the same fractions at small to moderate strains followed by an increase in the Brass component with an increase in total strains, especially, in the $304 \mathrm{~L}$ steel samples. On the other hand, the deformation martensite is characterised by the large fractions of $F(\{111\}<211>)$ and $I^{*}(\{223\}<110>)$ components. The $\mathrm{F}(\{111\}<211>)$ component is associated with martensitic transformation of the Brass oriented austenite, when the transformed martensite exhibits near $\mathrm{F}(\{111\}<211>)$ orientations in accordance with austenite-martensite orientation relationships, whereas the $I^{*}(\{223\}<110>)$ component tends to increase with increasing the rolling reduction due to operative slip systems of $\{110\}<111>$-type.

(4) The grain refinement during cold rolling leads to substantial strengthening, which can be expressed by a summation of the austenite and martensite strengthening contributions. Both the austenite and martensite strengthening contributions can be calculated through the respective mean grain size evolved during cold rolling.

\section{Acknowledgments}

The authors are grateful to the personnel of the Joint Research Centre, Belgorod State University, for their assistance with instrumental analysis.

\section{Disclosure statement}

AQ2 No potential conflict of interest was reported by the authors.

\section{ORCID}

Andrey Belyakov (D) http://orcid.org/0000-0001-9003-9416

\section{AQ3 References}

[1] K.H. Lo, C.H. Shek, and J.K.L. Lai, Recent developments in stainless steels, Mater. Sci. Eng. R Rep. 65 (2009), pp. 39-104.

[2] W. Martienssen and H. Warlimont, eds., Springer Handbook of Condensed Matter and Materials Data, Springer, Heidelberg, New York, 2005.

[3] J. Talonen and H. Hänninen, Formation of shear bands and strain-induced martensite during plastic deformation of metastable austenitic stainless steels, Acta Mater. 55 (2007), pp. 6108-6118.

[4] L. Bracke, G. Mertens, J. Penning, B.C. De Cooman, M. Liebeherr, and N. Akdut, Influence of phase transformations on the mechanical properties of high-strength austenitic Fe-Mn-Cr steel, Metall. Mater. Trans. A 37 (2006), pp. 307-317. 
[5] R.E. Schramm and R.P. Reed, Stacking fault energies of seven commercial austenitic stainless steels, Metall. Trans. A 6 (1975), pp. 1345-1351.

[6] G. Olson and M. Cohen, Kinetics of strain-induced martensitic nucleation, Met. Mater Trans A 6 (1975), pp. 791-795.

[7] N. Nakada, H. Ito, Y. Matsuoka, T. Tsuchiyama, and S. Takaki, Deformation-induced martensitic transformation behavior in cold-rolled and cold-drawn type 316 stainless steels, Acta Mater. 58 (2010), pp. 895-903.

[8] Y. Nakao and H. Miura, Nano-grain evolution in austenitic stainless steel during multidirectional forging, Mater. Sci. Eng. A 528 (2011), pp. 1310-1317.

[9] M. Abramova, N. Enikeev, R. Valiev, A. Etienne, B. Radiguet, Y. Ivanisenko, and X. Sauvage, Grain boundary segregation induced strengthening of an ultrafine-grained austenitic stainless steel, Mater. Lett. 136 (2014), pp. 349-352.

[10] I. Shakhova, A. Belyakov, Z. Yanushkevich, K. Tsuzaki, and R. Kaibyshev, On strengthening of austenitic stainless steel by large strain cold working, ISI Int. 56 (2016), pp. 1289-1296.

[11] S.V. Dobatkin, O.V. Rybalchenko, N.A. Enikeev, A.A. Tokar, and M.M. Abramova, Formation of fully austenitic ultrafine-grained high strength state in metastable Cr$\mathrm{Ni}$-Ti stainless steel by severe plastic deformation, Mater. Lett. 166 (2016), pp. 276-279.

[12] M. Odnobokova, M. Tikhonova, A. Belyakov, and R. Kaibyshev, Development of $\Sigma 3 n$ CSL boundaries in austenitic stainless steels subjected to large strain deformation and annealing, J. Mater. Sci. 52 (2017), pp. 4210-4223.

[13] A. Belyakov, A. Kipelova, M. Odnobokova, I. Shakhova, and R. Kaibyshev, Development of ultrafine grained austenitic stainless steels by large strain deformation and annealing, Mater. Sci. Forum 783-786 (2014), pp. 651-656.

[14] A. Belyakov, M. Odnobokova, I. Shakhova, and R. Kaibyshev, Regularities of microstructure evolution and strengthening mechanisms of austenitic stainless steels subjected to large strain cold working, Mater. Sci. Forum 879 (2016), pp. 224-229.

[15] M. Odnobokova, A. Belyakov, A. Kipelova, and R. Kaibyshev, Formation of ultrafinegrained structures in $304 \mathrm{~L}$ and $316 \mathrm{~L}$ stainless steels by recrystallization and reverse phase transformation, Mater. Sci. Forum 838-839 (2016), pp. 410-415.

[16] A.A. Tiamiyu, M. Eskandari, M. Sanayei, A.G. Odeshi, and J.A. Szpunar, Mechanical behavior and high-resolution EBSD investigation of the microstructural evolution in AISI 321 stainless steel under dynamic loading condition, Mater. Sci. Eng. A 673 (2016), pp. 400-416.

[17] R.E. Smallman and D. Green, The dependence of rolling texture on stacking fault energy, Acta Metall. 12 (1964), pp. 145-154.

[18] S.G. Chowdhury, S. Das, and P.K. De, Cold rolling behaviour and textural evolution in AISI 316L austenitic stainless steel, Acta Mater. 53 (2005), pp. 3951-3959.

[19] C. Donadille, R. Valle, P. Dervin, and R. Penelle, Development of texture and microstructure during cold-rolling and annealing of FCC alloys: example of an austenitic stainless steel, Acta Metall. 37 (1989), pp. 1547-1571.

[20] M. Nezakat, H. Akhiani, M. Hoseini, and J. Szpunar, Effect of thermo-mechanical processing on texture evolution in austenitic stainless steel 316L, Mater. Charact. 98 (2014), pp. $10-17$.

[21] C. Haase, S.G. Chowdhury, L.A. Barrales-Mora, D.A. Molodov, and G. Gottstein, On the relation of microstructure and texture evolution in an austenitic Fe-28Mn-0.28C TWIP steel during cold rolling, Metall. Mater. Trans. A 44 (2013), pp. 911-922.

[22] N.K. Tewary, S.K. Ghosh, S. Bera, D. Chakrabarti, and S. Chatterjee, Influence of cold rolling on microstructure, texture and mechanical properties of low carbon high $\mathrm{Mn}$ TWIP steel, Mater. Sci. Eng. A 615 (2014), pp. 405-415. 
[23] A.A. Saleh, C. Haase, E.V. Pereloma, D.A. Molodov, and A.A. Gazder, On the evolution and modelling of brass-type texture in cold-rolled twinning-induced plasticity steel, Acta Mater. 70 (2014), pp. 259-271.

[24] Z. Yanushkevich, A. Belyakov, C. Haase, D.A. Molodov, and R. Kaibyshev, Structural/ textural changes and strengthening of an advanced high-Mn steel subjected to cold rolling, Mater. Sci. Eng. A 651 (2016), pp. 763-773.

[25] D.B. Williams and C.B. Carter, Transmission Electron Microscopy Plenum, Springer, New York, 1996.

[26] M. Eskandari, A. Kermanpur, and A. Najafizadeh, Formation of nanocrystalline structure in 301 stainless steel produced by martensite treatment, Metall. Mater. Trans. A 40 (2009), pp. 2241-2249.

[27] M. Odnobokova, A. Belyakov, and R. Kaibyshev, Development of hanocrystalline $304 \mathrm{~L}$ stainless steel by large strain cold working, Metals. (Basel) 5 (2015), pp. 656-668.

[28] Y. He, S. Godet, and J.J. Jonas, Observations of the gibeon meteorite and the inverse greninger-troiano orientation relationship, J. Appl. Crystallogr. 39 (2006), pp. 72-81.

[29] D. Kuhlmann-Wilsdorf and N. Hansen, Geometrically necessary, incidental and subgrain boundaries, Scr. Metall. Mater. 25 (1991), pp. 1557-1562.

[30] B. Straumal, A. Korneva, and P. Zięba, Phase transitions in metallic alloys driven by the high pressure torsion, Arch. Civ. Mech. Eng. 14 (2014), pp. 242-249.

[31] R.D.K. Misra, B.R. Kumar, M. Somani, and P. Karjalainen, Deformation processes during tensile straining of ultrafine/nanograined structures formed by reversion in metastable austenitic steels, Scr. Mater. 59 (2008), pp. 79-82.

[32] M. Odnobokova, A. Belyakov, and R. Kaibyshev, Effect of severe cold or warm deformation on microstructure evolution and tensile behavior of a $316 \mathrm{~L}$ stainless steel, Adv. Eng. Mater. 17 (2015), pp. 1812-1820.

[33] W. Roberts, Microstructure evolution and flow stress during Hot working, in Strength of Metals and Alloys (ICSMA-7), H.J. McQueen, J.-P. Bailon, J.I. Dickson, J.J. Jonas, M.G. Akben, eds., Pergamon Press, Oxford, UK, 1986, pp. 1859-1892.

[34] J.J. Jonas, X. Quelennec, L. Jiang, and É. Martin, The avrami kinetics of dynamic recrystallization, Acta Mater. 57 (2009), pp. 2748-2756.

[35] A. Belyakov, M. Tikhonova, P. Dolzhenko, T. Sakai, and R. Kaibyshev, On kinetics of grain refinement and strengthening by dynamic recrystallization, Adv. Eng. Mater. (2018), doi:10.1002/adem.201800104, in press.

[36] M. Odnobokova, A. Belyakov, N. Enikeev, D.A. Molodov, and R. Kaibyshev, Annealing behavior of a 304L stainless steel processed by large strain cold and warm rolling, Mater. Sci. Eng. A 689 (2017), pp. 370-383.

[37] H.-R. Wenk and P.V. Houtte, Texture and anisotropy, Rep. Prog. Phys. 67 (2004), pp. 1367-1428.

[38] R.K. Ray, Rolling textures of pure nickel, nickel-iron and nickel-cobalt alloys, Acta Metall. Mater. 43 (1995), pp. 3861-3872.

[39] R. Madhavan, R.K. Ray, and S. Suwas, Micro-mechanical aspects of texture evolution in nickel and nickel-cobalt alloys: role of stacking fault energy, Philos. Mag. 96 (2016), pp. 3177-3199.

[40] V.V. Rybin, Large Plastic Deformations and Destruction of Metals, Metallurgia, Moscow, 1987.

[41] B. Bay, N. Hansen, D.A. Hughes, and D. Kuhlmann-Wilsdorf, Qverview no. 96 evolution of f.c.c. deformation structures in polyslip, Acta Metall. Mater. 40 (1992), pp. 205-219.

[42] F.J. Humphreys, P.B. Prangnell, J.R. Bowen, A. Gholinia, and C. Harris, Developing stable fine-grain microstructures by large strain deformation, Philos. Trans. Roy. Soc. Lond. A 357 (1999), pp. 1663-1681. 
[43] R.Z. Valiev, R.K. Islamgaliev, and I.V Alexandrov, Bulk nanostructured materials from severe plastic deformation, Prog. Mater. Sci. 45 (2000), pp. 103-189.

[44] T. Sakai, A. Belyakov, R. Kaibyshev, H. Miura, and J.J. Jonas, Dynamic and postdynamic recrystallization under hot, cold and severe plastic deformation conditions, Prog. Mater. Sci. 60 (2014), pp. 130-207.

[45] A. Morozova and R. Kaibyshev, Grain refinement and strengthening of a $\mathrm{Cu}-0.1 \mathrm{Cr}-$ $0.06 Z$ r alloy subjected to equal channel angular pressing, Philos. Mag. 97 (2017), pp. 2053-2076.

[46] J. Hirsch and K. Lücke, Overview no. 76: mechanism of deformation and development of rolling textures in polycrystalline fcc metals $-I$. description of rolling texture development in homogeneous CuZn alloys, Acta Metall. 36 (1988), pp. 2863-2882.

[47] J. Hirsch, K. Lücke, and M. Hatherly, Overview no. 76: mechanism of deformation and development of rolling textures in polycrystalline fcc metals-III. The influence of slip inhomogeneities and twinning, Acta Metall. 36 (1988), pp. 2905-2927.

[48] A. Kumar, R.K. Khatirkar, D. Chalapathi, N. Bibhanshu, and S. Suwas, Texture development during cold rolling of $\mathrm{Fe}-\mathrm{Cr}-\mathrm{Ni}$ alloy-experiments and simulations, Philos. Mag. 97 (2017), pp. 1939-1962.

[49] A. Belyakov, M. Murayama, Y. Sakai, K. Tsuzaki, M. Okubo, M. Eto, and T. Kimura, Development of a high-strength high-conductivity $\mathrm{Cu}-\mathrm{Ni}-\mathrm{P}$ alloy. part II: processing by severe deformation, J. Electron. Mater. 35 (2006), pp. 2000-2008.

[50] B.R. Kumar and M. Ghosh, Surface and mid-plane texture evolution in austenite phase of cold rolled austenitic stainless steels, Mater. Sci. Eng. A 457 (2007), pp. 236-245.

[51] Y. Lü, D.A. Molodov, and G. Gottstein, Correlation between microstructure and texture development in a cold-rolled TWIP steel, ISIJ Int. 51 (2011), pp. 812-817.

[52] C. Haase, T. Ingendahl, O. Güvenç, M. Bambach, W. Bleck, D.A. Molodov, and L.A. Barrales-Mora, On the applicability of recovery-annealed twinning-induced plasticity steels: potential and limitations, Mater. Sci. Eng. A 649 (2016), pp. 74-84.

[53] R.K. Ray, J.J. Jonas, and R.E. Hook, Cold rolling and annealing textures in low carbon and extra low carbon steels, Int. Mater. Rev. 39 (1994), pp. 129-172.

[54] F.J. Humphreys and M. Hatherly, Recrystallization and Related Annealing Phenomena, 2nd ed., Elsevier, Oxford, 2004.

[55] H. Kitahara, R. Ueji, M. Ueda, N. Tsuji, and Y. Minamino, Crystallographic analysis of plate martensite in Fe-28.5 at.\% Ni by FE-SEM/EBSD, Mater. Charact. 54 (2005), pp. 378-386.

[56] H. Kitahara, R. Ueji, N. Tsuji, and Y. Minamino, Crystallographic features of lath martensite in low-carbon steel, Acta Mater. 54 (2006), pp. 1279-1288.

[57] I. Shakhova, V. Dudko, A. Belyakov, K. Tsuzaki, and R. Kaibyshev, Effect of large strain cold rolling and subsequent annealing on microstructure and mechanical properties of an austenitic stainless steel, Mater. Sci. Eng. A 545 (2012), pp. 176-186.

[58] D.A. Hughes, and N. Hansen, Microstructure and strength of nickel at large strains, Acta Mater. 48 (2000), pp. 2985-3004.

[59] M.J. Starink, Dislocation versus grain boundary strengthening in SPD processed metals: Non-causal relation between grain size and strength of deformed polycrystals, Mater. Sci. Eng. A 705 (2017), pp. 42-45.

[60] Z. Yanushkevich, S.V. Dobatkin, A. Belyakov, and R. Kaibyshev, Hall-Petch relationship for austenitic stainless steels processed by large strain warm rolling, Acta Mater. 136 (2017), pp. 39-48.

[61] R.W. Armstrong, 60 years of hall-petch: past to present nano-scale connections, Mater. Trans. 55 (2014), pp. 2-12.

[62] A. Belyakov, Y. Kimura, and K. Tsuzaki, Microstructure evolution in dual-phase stainless steel during severe deformation, Acta Mater. 54 (2006), pp. 2521-2532. 